\title{
The Effect of Some Biological Parameters of Brevicoryne brassicae (L.) (Hemiptera: Aphididae) on Different Cauliflower Cultivars
}

\author{
Erol Bayhan \\ Dicle University, Agricultural Faculty, Diyarbakir Turkey \\ Selime Olmez Bayhan \\ Dicle University, Agricultural Faculty, Diyarbakir, Turkey \\ Helin Solhan \\ Dicle University, Agricultural Faculty, Diyarbakir, Turkey
}

\begin{abstract}
In this article, some biological parameters of Brevicoryne brassicae were studied on four different cauliflower cultivars (Casper RZ, Barcelona $F_{1}$, Karbeyaz $F_{1}$ and Mor karnabahar). This study was conducted under controlled conditions: $25 \pm 1{ }^{0} \mathrm{C}, 65 \pm 5 \%$ relative humidity (RH), and 16:8 (L:D) h photoperiods. The maximum and minimum developmental times were observed on Karbeyaz F1 and Barcelona $F_{1}$ cultivars, respectively. When we examine the total development period, the shortest Barcelona $F_{1}$ cultivar (6.73 days) and the longest total nymphal growth period were determined on Karbeyaz $\mathrm{F}_{1}$ (7.07 days). When the biological parameters of $B$. brassicae were examined, it was determined that the varieties with the lowest $r_{m}$ values were on Barcelona $\mathrm{F}_{1}$ cultivar. When the $R_{o}$ values are compared, it is seen that the lowest value is obtained in Barcelona $\mathrm{F}_{1}$ variety. When the $T_{o}$ values were examined, it was determined that the lowest value was obtained on Karbeyaz $\mathrm{F}_{1}$ variety, followed by Barcelona $\mathrm{F}_{1}$, Casper RZ and Mor karnabahar varieties.
\end{abstract}

Keywords: Brevicoryne brassicae, cauliflower cultivars, life table, biological parameters

DOI: $10.7176 / \mathrm{JSTR} / 6-13-09$

\section{Farklı Karnabahar Çeşitlerinin Lahana unlu yaprakbiti, Brevicoryne brassicae (L.) (Hemiptera: Aphididae)'nin Bazı Biyolojik Parametrelerine Etkisi}

Özet

$\mathrm{Bu}$ çalışma, Brevicoryne brassicae'nin bazı biyolojik parametreleri, dört farklı karnabahar çeşidi (Karbeyaz $\mathrm{F}_{1}$, Casper RZ, Mor karnabahar ve Barcelona $\mathrm{F}_{1}$ ) üzerinde yürütülmüştür. Çalışma kontrollü koşullar altında $\left(25 \pm 1{ }^{0} \mathrm{C}\right.$ sicaklık, \% $65 \pm 5$ nispi nem, uzun gün aydınlatma) gerçekleşmiştir. Toplam gelişme süresi kapsamında incelediğimizde ise en kısa Barcelona $F_{1}$ çeşidinde (6.73 gün), en uzun toplam nimf gelişme süresi ise Karbeyaz F1 ( 7.07 gün) çeşidi üzerinde bulunmuştur. B. brassicae'nin bazı biyolojik parametrelerini incelendiğinde $r_{m}$ değerlerinin en düşük olduğu çeşidin Barcelona F1 çeşidinde olduğu hesaplanmıştır. Ele alınan çeşitler arasında $R_{o}$ değerleri kıyaslandığında ise Barcelona $\mathrm{F}_{1}$ çeşidinde en düşük değeri tespit edilmiştir. $T_{o}$ değerleri incelendiğinde ise en düşük değerin Karbeyaz $F_{1}$ çeşidinde elde edildiği, bunu sırasıyla Barcelona $F_{1}$, Casper RZ ve Mor karnabahar çeşitlerinin izlediği tespit edilmiştir.

Anahtar Kelimeler: Brevicoryne brassicae, karnabahar çeşitleri, yaşam çizelgesi, biyolojik parametreler 


\section{Giriş}

Türkiye'de önemli bir yere sahip olan sebze tarımı, günümüz ülke nüfusunun yılda ortalama \%2 civarında artmaya devam etmesiyle daha da önem kazanmıştır. Bugün, insan yaşamı için dengeli beslenmenin sebzesiz olamayacağı, sağlıklı ve dengeli beslenmenin ana unsurlarından birinin sebze tüketimi olduğu herkes tarafindan bilinmektedir. Bu sebeple sebze üretiminde en iyi, en yüksek verim ve kalite yakalama çalışmaları ve bunun için yapılan geliştirme faaliyetleri, dünyada ve ülkemizde çok hızlı bir şekilde ilerlemeye devam etmektedir. Hem işlenerek, hem de taze olarak değerlendirilen tek veya çok yıllık otsu bitkiler olan sebzelerin, kök, gövde, sürgün, yaprak, çiçek, meyve ve tohum gibi bütün kısımları gıda kaynağıdır. Doyurucu özellikleri nedeniyle önemli bir diyet yiyeceği olan sebzeler, düşük yă̆ içeriğine sahip olup, vitamin, mineral madde, karbonhidrat ve protein kaynağıdır. Brassicacea familyası içerisinde karnabahar yetiştiriciliği ise, dünyada 1.147 .559 ha'lık alanda yapılmış ve üretim 19.845.519 ton civarında olmuştur (172.936 ton/ha). Karnabahar üretiminde Çin 8.267.877 ton ile dünyada birinci sırada bulunurken, Türkiye 150.843 ton üretimle 14. sırada yer almıştır (TÜİK, 2010).

Yaprakbitlerinin biyolojisi, populasyon değişimi ve zararı üzerine konukçu çeşidinin önemli bir etkisi vardır (Ulusoy ve Ölmez Bayhan, 2006; Akça ve ark., 2015; Yazıcı ve Akça, 2016). Özellikle Lahana unlu yaprakbiti, Brevicoryne brassicae (L.) (Hemiptera: Aphididae) lahana, karnabahar, brokoli, hardal ve kolzada yoğun popülasyon oluşturmaktadır. Zararlının beslendiği bitkilerde gelişme durur, yapraklar kıvrılır ve renk bozuklukları görülür. Nimflerin gömlekleri, salgıladıkları ballımsı maddelere yapışarak bitki üzerinde kalır ve bu da fumajin ile birlikte sebzelerin pazar değerini büyük ölçüde düşürür (Kılınçer, 1982; Lodos, 1982, Zeren, 1989). Kennedy ve ark. (1962), B. brassicae'nin çeşitli bitkilere 28 kadar virüs hastalığını taşıdığını belirtmiştir. Diğer taraftan bu zararlının Çukurova bölgesinde de Cruciferae familyasına bağlı sebzelerde yaygın olarak görüldüğü ve önemli ürün kayıplarına neden olduğu bildirilmiştir (Zeren ve Düzgüneş, 1984).

Tarım alanlarındaki kullanılan ilaçlara karşı zararlılarda meydana gelen direnç, günümüzde çok önemli problemler olarak çözülmeyi beklemektedir. Bir çok araştırıcı bilinçsiz ve gereksiz kullanılan bu pestisitlerin zararlılarda direnç oluşumuna sebep olmasının yanı sıra doğal düşmanlar üzerine olumsuz bir çok etkiye neden olduğunu, dolayısıyla selektif ilaçların mutlaka kullanılması gerektiğini vurgulamışlardır (Ayyıldız ve Atlıhan, 2006; Afshari ve ark., 2009). Günümüzde 553 türün en azından bir insektisit veya akarisite karşı direnç kazanmış durumda olduğu kaydedilmektedir (Anonim 2007).

Konukçu bitki dayanıklılığı hastalık ve zararlılarla mücadelede önemli bir yol olarak bilinmektedir. Bu çalışma ile cruciferlerin önemli zararlısı olan B. brassicae'nin mücadelesinde farklı karnabahar çeşitlerindeki beslenme sonucu oluşan reaksiyon özelliklerinden yararlanılarak, zararlıya karşı hangi bitkinin daha duyarlı olduğunu yönelik biyolojik parametreleri saptanmıştır.

\section{Materyal ve Yöntem \\ Konukçu Bitki Üretimi:}

Denemelerde kullanılacak Brevicoryne brassicae'yi üretmek için çalışma boyunca farklı karnabahar çeşitlerinin (Karbeyaz F1, Casper RZ, Mor karnabahar ve Barcelona F1) yetiştirilmesi iklim odalarında yapılmıştır. Bu amaçla her bir bitkiye ait tohumlar 12 × $22 \mathrm{~cm}$ 'lik küvetlere ayrı ayrı ekilmiş ve daha sonra gerçek yaprakları oluşan fideler denemelerde kullanılmıştır. Böylece, deneme boyunca kullanılan konukçu bitkilerin 15 günde bir ekim işlemleri yapılmıştır.

Bütün laboratuvar çalışmaları $25 \pm 1{ }^{0} \mathrm{C}$ sıcaklık, \% $65 \pm 5$ orantılı nem ve uzun gün aydınlatmalı (16: 8) iklim odası koşullarında yapılmıştır. Dicle Üniversitesi Ziraat Fakültesi Bitki Koruma Bölümü Entomoloji laboratuvarındaki mevcut lahana unlu yaprakbiti denemelerde kullanılmıştır. Laboratuvarda mevcut bitkiler yaprakbiti popülasyonundan alınan erginler 55x55x60 cm büyüklüğünde kafeslerde her birinde bir küvet olacak şekilde her çeşitten birer kafes olmak üzere 3 kafes oluşturulmuştur. Böylece iklim odasında farklı karnabahar çeşitlerinin yetiştirilerek kafeslerin içinde $B$. brassicae üretiminin devamlılığı sağlanmıştır. B. brassicae üretiminin devamlılığını sağlamak amacıyla bitki üretim odasından gerek duyulduğunda böcek üretimi odasındaki tül kafeslere yeni bitkiler aktarılmıştır.

\section{Brevicoryne brassicae Üretimi:}

Bütün laboratuvar çalışmaları $25 \pm 1{ }^{0} \mathrm{C}$ sıcaklık, \% $65 \pm 5$ orantılı nem ve uzun gün aydınlatmalı (16: 8) iklim odası koşullarında yürütülmüştür. Dicle Üniversitesi Ziraat Fakültesi Bitki Koruma Bölümü

70 | P a g e

www.iiste.org 
Entomoloji laboratuvarındaki mevcut yaprakbiti denemelerde kullanılmışıtır.

\section{Laboratuvar Çalışmaları:}

Laboratuvarda mevcut yaprakbiti popülâsyonundan alınan erginler petri kaplarında bulunan farklı karnabahar çeşitleri üzerine bırakılıp günlük gelişimleri izlenmiş ve elde edilen bilgiler kaydedilmiştir. Daha sonra binoküler mikroskop altında incelenen $B$. brassicae nimfleri de farklı petri kaplarına alınıp gelişimleri kontrol edilmiştir

\section{Brevicoryne brassicae'nin Farklı Karnabahar Çeşitleri Üzerindeki Ergin ve Ergin Öncesi Dönemlerinin Gelişme Süresi}

Brevicoryne brassicae'nin karnabahar çeşitleri (Karbeyaz F1, Casper RZ, Mor karnabahar ve Barcelona F1) üzerindeki biyolojileri iklim odalarında $25 \pm 1{ }^{\circ} \mathrm{C}$ sabit sicaklık, $\% 65 \pm 5$ orantılı nem, uzun gün aydınlatmalı (16: 8) koşullarda yürütülmüştür (Resim 1). karnabahar çeşitleri (Karbeyaz F1, Casper RZ, Mor karnabahar ve Barcelona F1) üzerindeki yürütülmüş olan çalışmada B. brassicae'nin $\mathrm{F}_{1}$ bireyleri denemeye alınmıştır. Denemeye alınan bir günlük nimfler $9 \mathrm{~cm}$ çap ve $1,5 \mathrm{~cm}$ yüksekliğindeki her bir petri kutusu içerisinde bir adet nimf olacak şekilde, sıfır numaralı samur firça yardımıyla çapına göre kesilmiş bitki yaprağı diskleri üzerine bırakılmıştır (Resim 2). Petri kutuları içerisine konulan bitkilere ait yaprakları uzun süre canlı tutabilmek için petri tabanına kurutma kağıdı konulmuş ve hafif ıslak tutacak kadar su verilmiştir. Denemeye alınan bir günlük nimflerin bulunduğu petriler günde iki kez (sabah ve akşam) aynı saatlerde olmak koşuluyla kontrol edilmiş ve gömlek değiştiren bireylerin gömlekleri ortamdan uzaklaştırılarak dönemleri kaydedilmiştir.

\section{Brevicoryne brassicae'nin Farklı Karnabahar Çeşitleri Üzerindeki Ölüm Oranı}

Yukarıdaki denemede günlük olarak izlenen B. brassicae'nin ele alınan karnabahar çeşitleri (Karbeyaz F1, Casper RZ, Mor karnabahar ve Barcelona F1) üzerinde biyolojisi incelenirken meydana gelen ölümler günlük olarak kaydedilmiştir. Zararlıya ait her dönemdeki ölüm yüzdeleri hesaplanmıştır.

\section{Verilerin Değerlendirilmesi:}

Zararlıya ait yaşam çizelgesi Birch (1948)'ün önerdiği, Howe (1953) ve Watson (1964)'ın geliştirdiği formüle göre oluşturulacaktır. Yaşam çizelgesindeki verilerden, temel ekolojik parametre olan kalitsal üreme yeteneği, $r_{m} ; \Sigma e^{-r m . x} \cdot l_{x} \cdot m_{x}=1$ eşitliğinden yararlanılarak hesaplanacaktır. Formülde (e), doğal logaritma tabanını; (x), dişi bireylerin gün olarak yaşını; $\left(1_{x}\right)$, x yaştaki bireylerin 1'e göre canlılık oranını, $\left(\mathrm{m}_{\mathrm{x}}\right)$ ise günlük dişi başına bırakılan dişi yavru sayısını göstermektedir. Diğer parametre olan Ro ise, $\left(l_{\mathrm{x}}\right)$ ve $\left(\mathrm{m}_{\mathrm{x}}\right)$ değerlerinin günlük çarpımlarının toplamı ile oluşturulmuştur. Bu verilerin elde edilmesinden sonra ortalama döl süresi Laing (1968) eşitliğinden To $=\log _{\mathrm{e}}$ Ro/ $\mathrm{r}_{\mathrm{m}}$ elde edilmiştir. Yapılan çalışmalar sonucunda elde edilen verilerin istatistiksel analizleri uygun programlarla (Twosex programı) analiz edilmiştir (Chi, 1997).

Yapılan çalı̧̧malar sonucunda elde edilen verilerden istatistiksel analiz gerektirenler uygun programlarla (SPSS version 13.0) analiz edilmiştir.

\section{Sonuç}

Çalı̧̧mada ele alınan farklı karnabahar çeşitlerinden (Karbeyaz F1, Casper RZ, Mor karnabahar ve Barcelona F1) elde edilen sonuçlar değerlendirilmiş ve aşağıda verilmiştir (Tablo 1, 2, 3).

Ergin öncesi gelişme dönemleri ayrı ayrı ele alındığında 1. nimf gelişme süresinin en kısa 1.43 gün ile Karbeyaz F1 çeşidinde elde edildiği görülmektedir (Tablo 1). Bunu 1.50 gün ile Barcelona F1 çeşidinde,1.62 gün ile Mor karnabahar çeşidinde ve 1.78 gün ile de Casper RZ çeşidinde takip ettiği görülmektedir. İkinci nimf gelişme süreleri karşılaştırıldığında ise en kısa gelişme süresinin 1.65 gün ile Barcelona F1 çeşidinde ve 1.67 gün ile de Casper RZ çeşidinde olduğu görülmüştür. Üçüncü dönem nimfin gelişme süresi incelendiğinde ise en az 1.75 gün ile Karbeyaz F1 çeşidinde, 1.78 gün ile Mor karnabahar çeşidinde, 1.94 gün ile Casper RZ çeşidinde ve 2.18 gün ile Barcelona F1 çeşidinde

71 I P a g e 
tamamladığı tespit edilmiştir. Dördüncü nimf dönemini ise en kısa Barcelona F1 çeşidinde (1.47 gün) en uzun ise Karbeyaz F1 çeşidinde (1.73 gün) tamamladığı görülmektedir (Tablo 1). Ergin Öncesi toplam gelişme süreleri incelendiğinde $B$. brassicae'nin en kısa 6.73 gün ile Barcelona F1 çeşidinde, en uzun ise 7.07 gün ile Karbeyaz F1 çeşidinde tamamladığı tespit edilmiş̧ir (Tablo 1).

Brevicoryne brassicae'nin ergin öncesi gelişme süresini Ölmez Bayhan (2004) lahana, lahanada 10.4 gün, Ölmez Bayhan ve Ulusoy (2006) karnabaharda 8.90 gün olarak bulduklarını belirtmişlerdir. Bu çalışmalardan elde edilen bulgular ile farklılık gösterdiği görülmektedir.

Tablo 1. Brevicoryne brassicae'nin ergin öncesi dönemlerinin farklı karnabahar çeşitleri (Karbeyaz F1, Casper RZ ve Barcelona F1) üzerindeki biyolojik parametreleri (gün).

\begin{tabular}{lcccc}
\hline Biyolojik Dönemler & Karbeyaz F1 & Casper RZ & $\begin{array}{c}\text { Mor } \\
\text { karnabahar }\end{array}$ & Barcelona F1 \\
\hline 1. nimf & $1.43 \pm 0.17 \mathrm{a}$ & $1.78 \pm 0.18 \mathrm{a}$ & $1.62 \pm 0.15 \mathrm{a}$ & $1.50 \pm 0.17 \mathrm{a}$ \\
2. nimf & $2.05 \pm 0.29 \mathrm{~b}$ & $1.67 \pm 0.17 \mathrm{a}$ & $1.68 \pm 0.19 \mathrm{a}$ & $1.65 \pm 0.13 \mathrm{a}$ \\
3. nimf & $1.75 \pm 0.21 \mathrm{a}$ & $1.94 \pm 0.16 \mathrm{ab}$ & $1.78 \pm 0.17 \mathrm{a}$ & $2.18 \pm 0.12 \mathrm{~b}$ \\
4. nimf & $1.73 \pm 0.31 \mathrm{a}$ & $1.60 \pm 0.27 \mathrm{a}$ & $1.61 \pm 0.24 \mathrm{a}$ & $1.47 \pm 0.19 \mathrm{a}$ \\
Ergin öncesi dönem & $7.07 \pm 0.65 \mathrm{a}$ & $6.87 \pm 0.46 \mathrm{a}$ & $6.84 \pm 0.52 \mathrm{a}$ & $6.73 \pm 0.41 \mathrm{a}$ \\
\hline
\end{tabular}

* Ortalamalar arasındaki fark soldan sağa doğru izlendiğinde aynı harfi içermiyorsa Duncan testine göre istatistiki olarak önemlidir $(\mathrm{P}=0.05)$.

Ergin bireylerin yaşam süreleri kıyaslandığında en uzun Casper RZ çeşidinde (3.13 gün), en kısa ise Karbeyaz F1 çeşidinde (1.20 gün) yaşadığı tespit edilmiştir (Tablo 2). B. brassicae'nin verdiği yavru sayıları bu çalışmada ele alınan karnabahar çeşitlerinde birbirleriyle kıyaslandıklarında ise en çok Casper RZ çeşidinde (22.40 yavru/dişi), en az yavru sayısının ise Karbeyaz F1 çeşidinde (0.64 yavru/dişi) elde edildiği görülmektedir (Tablo 2).

Tablo 2. Brevicoryne brassicae'nin farklı karnabahar çeşitleri (Karbeyaz F1, Casper RZ ve Barcelona F1) üzerindeki ergin dönemleri (gün) ve yavru sayıları (adet).

\begin{tabular}{lcccc}
\hline Biyolojik Dönemler & Karbeyaz F1 & Casper RZ & Mor karnabahar & Barcelona F1 \\
\hline Ergin & $1.20 \pm 0.10 \mathrm{a}$ & $3.13 \pm 0.54 \mathrm{~b}$ & $1.28 \pm 0.11 \mathrm{a}$ & $2.20 \pm 0.22 \mathrm{ab}$ \\
Total longevity & $7.43 \pm 0.58 \mathrm{a}$ & $8.83 \pm 0.65 \mathrm{a}$ & $8.54 \pm 0.52 \mathrm{a}$ & $8.35 \pm 0.58 \mathrm{a}$ \\
Yavru sayıs1 & $0.64 \pm 0.46 \mathrm{a}$ & $22.40 \pm 10.62 \mathrm{c}$ & $4.98 \pm 2.13 \mathrm{~b}$ & $4.93 \pm 2.13 \mathrm{~b}$
\end{tabular}

* Ortalamalar arasındaki fark soldan sağa doğru izlendiğinde aynı harfi içermiyorsa Duncan testine göre istatistiki olarak önemlidir $(\mathrm{P}=0.05)$.

Brevicoryne brassicae'nin bazı biyolojik parametrelerini incelendiğinde $r_{m}$ değerlerinin en düşük olduğu karnabahar çeşidinin Barcelona F1 olduğu (0.144034) ve bunu sırasıyla Casper RZ çeşidinde (0.245941) ve Karbeyaz F1 çeşidinde (0.430000) izlediği görülmektedir (Tablo 3). Ele alınan farklı karnabahar çeşitleri arasında $R_{o}$ değerleri kıyaslandığında ise en düşük değerin Barcelona $F 1$ çeşidinde (3.70) ve en yüksek değerin ise Casper RZ çeşidinde (14.68) elde edildiği görülmektedir (Tablo 3). Bu araştırmada To değerleri incelendiğinde ise en düşük değerin Karbeyaz F1 çeşidinde (7.51) elde edildiği, bunu sırasıyla Barcelona F1 çeşidinde (9.08) ve Casper RZ çeşidinde (10.90) izlediği tespit edilmiştir (Tablo 3). 
Tablo 3. Brevicoryne brassicae'nin farklı karnabahar çeşitleri (Karbeyaz F1, Casper RZ ve Barcelona F1) üzerindeki biyolojik parametreleri.

\begin{tabular}{lcccc}
\hline Biyolojik Dönemler & Karbeyaz F1 & Casper RZ & Mor karnabahar & Barcelona F1 \\
\hline $\mathrm{r}_{\mathrm{m}}$ & 0.430000 & 0.245941 & 0.223127 & 0.144034 \\
$\mathrm{R}_{\mathrm{o}}$ & 11.28 & 14.68 & 13.32 & 3.70 \\
$\mathrm{~T}_{\mathrm{o}}$ & 7.51 & 10.90 & 11.84 & 9.08 \\
\hline
\end{tabular}

Brevicoryne brassicae'nin Farklı Karnabahar Çeşitleri Üzerindeki Ölüm Oranı

Brevicoryne brassicae'nin çalışmada ele alınan farklı karnabahar çeşitlerinden (Karbeyaz F1, Casper RZ ve Barcelona F1) elde edilen ölüm sonuçları (mortality) sonuçları Tablo 4'te verilmiştir. Ele alınan karnabahar çeşitleri arasında en yüksek orada ölümün Casper RZ çeşidinde, en düşük orandaki ölümün ise Barcelona F1 çeşidinde görüldüğü tespit edilmiştir.

Tablo 4. Brevicoryne brassicae'nin farklı karnabahar çeşitleri (Karbeyaz F1, Casper RZ ve Barcelona F1) üzerindeki ölüm oranları (\%).

\begin{tabular}{lcccc}
\hline Biyolojik Dönemler & Karbeyaz F1 & Casper RZ & Mor karnabahar & Barcelona F1 \\
\hline Ölüm Oranı & 0.2857 & 0.3478 & 0.3027 & 0.2500 \\
\hline
\end{tabular}

\section{Teşekkür}

Bu çalışmanın yürütülmesine maddi destek sağlayan TÜBİTAK (2209A kod numaralı)'a teşekkür ederiz.

\section{Kaynaklar}

Afshari, A.; Negadian E. S.; and Shsihebor P.; (2009). Population Density and Spatial Distribution of Aphis gossypii Glover (Homoptera: Aphididae) on Cotton in Gorgan, Iran. J. Agric. Sci. Technol. (2009) Vol. 11: 27-38.

Akca, I., Ayvaz T., Yazici, E., Smith, C.L., Chi, H., 2015. Demography and Population Projection of Aphis fabae (Hemiptera: Aphididae): with Additional Comments on Life Table Research Criteria. Journal of Economic Entomology, 2: 1-13.

Anonim, 2007. Arthropod Pesticide Resistance Database.http://www. pesticideresistance. Org /search /1/5.

Ayyıldız, Y.; Atlıhan, R.; (2006). Balıkesir İli Sebze Alanlarında Görülen Yaprakbiti Türleri ve Doğal Düşmanları. Y.Y.Ü. Ziraat Fakültesi, Tarım Bilimleri Dergisi (J. Agric. Sci.), 2006, 16 (1): 1-5.Gadomski, H., Kelm, M., Gabrys, B. and Grzadkowska, A., (1996). Brassica Vegetables as Host Plants for the Cabbage Aphid (Brevicoryne brassicae L.). In International Symposoium on Pests of Brassica crops, Skierniewice, Poland, 22-23 Ocober, 99-104.

Birch, L. C. 1948. The intrinsic rate of natural increase of an insect population. J. Anim. Ecol. 17: $15-26$.

Chi H (1997) Age-stage, two-sex life table analysis. http://140.120.197.173/Ecology /Download/Twosex.zip

73 | $\mathrm{P}$ a g e

www.iiste.org 
Fathipour, Y., A. Hosseini, A. A. Talebi, S. Moharramipour, and S. Asgari. 2005. Effects of different temperatures on biological parameters of cabbage aphid, Brevicoryne brassicae (Hom.: Aphididae). J. Sci. Technol. Agric. Nat.Resour. Water Soil Sci., 9: 185-194.Howe W., 1953. The rapid determination of the intrinsic rate of increas of an insect population. Ann. Appl. Biol 40: $134-151$.

Kennedy JS, Day MF, Eastop VF (1962). A Conspectus of Aphids as Vector of Plant Viruses. Commenwealth Inst. Ent. London. 114pp

Kılınçer, N., (1982). Ankara'da Lahana yaprakbiti (Brevicoryne brassicae (L.)-Homoptera: Aphididae)'nin Parazit Kompleksi Üzerinde Araştırmalar. Bitki Koruma Bülteni, 22 (3): 1-12 s.

Lodos, N., (1982). Türkiye Entomolojisi II. Genel, Uygulamalı ve Faunistik. Ege Üniv. Zir. Fak. Yayınları No. 429, İzmir, 591s.

Ölmez Bayhan, S. 2004. Çukurova Bölgesi’nde Lahana Unlu Yaprakbiti Brevicoryne brassicae (L.) (Homoptera: Aphididae)'nin Bazı Konukçularda Biyolojisi ve Parazitoidi Diaeretiella rapae (M'intosh) (Hymenoptera: Aphididae)'nin Populasyon Gelişmesi İle Aralarındaki İlişkilerin Belirlenmesi. Çukurova Üniversitesi, Fen Bilimleri Enstitüsü, Doktora Tezi, Adana.

Ölmez Bayhan, S. ve Ulusoy, M.R. 2006. Effect of certain Brassica plants on biology of the cabbage aphid, Brevicoryne brassicae under laboratory conditions. Phytoparasitica, 34: 133138.

Türkiye İstatistik Kurumu, TÜİK., 2010

Ulusoy, M. R. and S. Ölmez-Bayhan, (2006). Effect of certain Brassica Plants on Biology of the Cabbage Aphid Brevicoryne brassicae under Laboratory Conditions. Phytoparasitica, 34 (2): 133-138.

Yazıcı, E. ve Akça, İ., 2016. Aphis gossypii Glover (Hemiptera: Aphididae)'nin farklı patlıcan çeşitlerinde bazı biyolojik parametrelerinin belirlenmesi. Anadolu Tarım Bilim. Derg./Anadolu J Agr Sci 31.

Zeren, O., (1989). Çukurova Bölgesinde Sebzelerde Zararlı Olan Yaprakbitleri (Aphidoidea) Türleri, Konukçuları, Zararları ve Doğal Düşmanları Üzerinde Araştırmalar. Tar. Orm. ve Köyişleri Bak. Araştırma Yayınları Serisi Yayın No.59, 205s.

Zirai Mücadele Teknik Talimatı, (2006). Kasım, Antalya. 